\title{
- Lexical and Phonological Processes in Dyslexic Readers: Evidence from a Visual Lexical Decision Task
}

\author{
Susana Araújo '**, Luís Faísca', Inês Bramão', Karl Magnus Petersson ',2,3 \\ and Alexandra Reis' \\ 'Cognitive Neuroscience Research Group, Departamento de Psicologia, \& Institute of Biotechnology \\ \& Bioengineering, Centre for Molecular and Structural Biomedicine, Universidade do Algarve, Faro, \\ Portugal \\ ${ }^{2}$ Max Planck Institute for Psycholinguistics, Nijmegen, The Netherlands \\ ${ }^{3}$ Donders Institute for Brain, Cognition and Behaviour, Radboud University, Nijmegen, The \\ Netherlands
}

\begin{abstract}
The aim of the present study was to investigate whether reading failure in the context of an orthography of intermediate consistency is linked to inefficient use of the lexical orthographic reading procedure. The performance of typically developing and dyslexic Portuguese-speaking children was examined in a lexical decision task, where the stimulus lexicality, word frequency and length were manipulated. Both lexicality and length effects were larger in the dyslexic group than in controls, although the interaction between group and frequency disappeared when the data were transformed to control for general performance factors. Children with dyslexia were influenced in lexical decision making by the stimulus length of words and pseudowords, whereas age-matched controls were influenced by the length of pseudowords only. These findings suggest that non-impaired readers rely mainly on lexical orthographic information, but children with dyslexia preferentially use the phonological decoding procedure-albeit poorly-most likely because they struggle to process orthographic inputs as a whole such as controls do. Accordingly, dyslexic children showed significantly poorer performance than controls for all types of stimuli, including words that could be considered over-learned, such as high-frequency words. This suggests that their orthographic lexical entries are less established in the orthographic lexicon. Copyright (c) 2013 John Wiley \& Sons, Ltd.
\end{abstract}

Keywords: dyslexia; lexical decision; reading

\section{INTRODUCTION}

Learning to read requires the acquisition of various skills, including orthographic and phonological decoding skills, as well as perceptual and semantic-pragmatic knowledge (Treiman, 2000; Vellutino, Fletcher, Snowling, \& Scanlon, 2004). One of the most important concerns has been why some individuals with normal intelligence and adequate educational opportunities suffer persistent and severe

\footnotetext{
*Correspondence to: Susana Araújo, Cognitive Neuroscience Research Group, Departamento de Psicologia \& Institute of Biotechnology \& Bioengineering, Centre for Molecular and Structural Biomedicine, Universidade do Algarve, Faro 8005-139, Portugal. E-mail: smaraujo@ualg.pt
} 
difficulties learning to read, a so-called condition known as developmental dyslexia (DYS). In the context of the dual-route framework (Castles, Bates, Coltheart, Luciano, \& Martin, 2006; Coltheart, 2007; Coltheart, Rastle, Perry, Langdon, \& Ziegler, 200I), reading difficulties stem from either deficits in the lexical (also called 'orthographic') or the sublexical (also called 'phonological') processing route or both. The lexical route directly maps the whole-word orthographic configuration to word phonology in the mental lexicon, whereas the sublexical route is required for phonological decoding. However, the majority of developmental studies on reading disorders have suggested that DYS is primarily related to difficulties or inefficiencies in the sublexical decoding procedure at the grapheme-phoneme level (Beech \& Awaida, 1992; Grainger, Bouttevin, Truc, Bastien, \& Ziegler, 2003; Harm \& Seidenberg, 1999; Ramus et al., 2003).

One of the hallmarks of a decoding deficit is a stronger lexicality effect (the superiority of words over pseudowords) in participants with DYS compared with control readers, that is, dyslexics exhibit a special disadvantage in reading unfamiliar words and pseudowords compared with words (e.g. Harm \& Seidenberg, 1999; Rack, Snowling, \& Olson, 1992; Sprenger-Charolles, Colé, Lacert, \& Sernicales, 2000). This pattern of results suggests a fragility in sequential phonological decoding because words can be read via lexical processes not available to pseudowords (but see Van den Broeck \& Geudens, 2012 for a re-interpretation of non-word reading deficit findings). However, Ziegler and colleagues (2008) maintained that phonological deficits in DYS affect processing via both the lexical (for example, in access to the phonological lexicon) and the sublexical route. Accordingly, a deficit in irregular word reading (i.e. a regularity effect) is well-documented in English-speaking children with DYS (for a review, see Metsala, Stanovich, \& Brown, 1998), which may suggest impaired access to the lexicon.

Over the past decade, it has become clear that the orthographic consistency of a writing system (i.e. the transparency of its letter-sound mappings) might impact the cognitive dynamics of reading development across languages (e.g. Vaessen et al., 2010; Ziegler et al., 2010), which leads to the possibility that the characteristics of a reading disorder might depend greatly on the structure (opaque versus transparent) of its orthography. Because much of the previous research has been conducted in English, which is an unusually irregular orthography, the implication may be that subjects with DYS in a transparent orthography with direct correspondence rules might not conform to the pattern shown in an opaque orthography such as English. For example, English-speaking dyslexics would be expected to show more deficits in sublexical decoding strategies based on the fact that the grapheme-to-phoneme relations are much more complex in English compared with transparent orthographies.

Recent studies on transparent orthographies lend support to this idea. For example, studies using Spanish-speaking, Italian-speaking and German-speaking samples have shown that dyslexics' non-word reading accuracy approaches normal performance, and non-word deficits mainly show up in reading-speed scores (Di Filippo, De Luca, Judica, Spinelli, \& Zoccolotti, 2006; Gonzalez \& Valle, 2000; Zoccolotti et al., 1999; Wimmer, 1993, 1996). This contrasts with the Englishspeaking pattern of low accuracy and speed for non-word reading (ljzendoorn \& Bus, 1994; Rack et al., 1992). Several other studies have reported no strong effects of lexicality in dyslexics' reading in transparent orthographies (e.g. Di Filippo et al., 2006; Zoccolotti, De Luca, Judica, \& Spinelli, 2008), which contradicts a specific 
deficit in non-word reading (at least in terms of accuracy) that is often reported for English-speakers. Additionally, the topic has been addressed in a few cross-language investigations, which typically have compared reading development in English and one other language. The results have been mixed. Landerl, Wimmer and Frith (1997) observed that German-speaking children with DYS read high-frequency and low-frequency words equally well, whereas the low-frequency words produced higher error rates for the English-speaking dyslexic children. Because rare words would most likely be read by sequential grapheme-to-phoneme conversion (because they have no representations in the subjects' internal lexicon), these results suggest that DYS in a transparent orthography does not prevent the development of good decoding abilities, which happens in English. As a consequence, reading accuracy in transparent orthographies is typically normal, and DYS is mainly characterized by dysfluency (e.g. de Jong \& van der Leij, 1999; Landerl et al., 1997; for an overview see Wimmer \& Schurz, 2010). However, in a German-English comparison by Ziegler and colleagues, both groups with DYS were found to be affected by variables such as lexicality to a similar extent (Ziegler, Perry, Ma-Wyatt, Ladner, \& Schulte-Körne, 2003).

On the grounds of the dual-route theory, dyslexic speed impairments in transparent orthographies have been traced to a persistent use of a (time-consuming) sublexical decoding strategy instead of progressing towards a reliance on more efficient parallel word recognition strategies, as in normal reading development (De Luca, Borrelli, Judica, Spinelli, \& Zoccolotti, 2002; Zoccolotti et al., 2005, 1999). This is supported by the outcomes of studies that examined the word length effect (i.e. longer response times (RTs) to long stimuli than short stimuli), a marker for a serial sublexical decoding strategy. Although this effect has been found to decrease with age in normal reading development, the same is not true for dyslexic readers (De Luca, Barca, Burani, \& Zoccolotti, 2008; Judica, De Luca, Spinelli, \& Zoccolotti, 2002; Spinelli et al., 2005; Zoccolotti et al., 2005). Similarly, large length effects were reported for German-speaking and English-speaking dyslexics by Ziegler and colleagues (2003) using a naming paradigm.

Dyslexics' reliance on a sublexical routine may be due to the lexical procedure being less available because of a lack of orthographic knowledge or a deficient access to the orthographic lexicon (Zoccolotti et al., 2005). Indeed, impaired readers perform poorly on tasks mapping the lexical procedure, such as orthographic decisions (Bergmann \& Wimmer, 2008) and orthographic judgement tasks (Marinelli, Angelelli, Notarnicola, \& Luzzatti, 2009). Results consistent with this interpretation were obtained by examining vocal RTs to word-naming (Marinus \& de Jong, 20I0; Paizi, Burani, De Luca, \& Zoccolotti, 20II) and eyemovement recording (De Luca et al., 2002; Hawelka, Gagl, \& Wimmer, 2010; Zoccolotti et al., 1999), although some studies dispute this viewpoint. For example, studies examining the effect of word frequency (a marker of reliance on the lexical reading route) indicate that the performance of both Italian dyslexic and control children is influenced by this effect, that is, high-frequency words were named faster than low-frequency ones (Barca, Burani, Di Filippo, \& Zoccolotti, 2006; De Luca et al., 2008). Therefore, these results seem to support the preservation of lexical activation in Italian-speaking dyslexic readers.

In summary, on the basis of the reviewed evidence, it is clear that a universal account of reading problems in DYS requires a detailed understanding of how reading deficits occur as a function of the consistent-inconsistent orthographic 
continuum. However, most approaches to understanding cross-language differences in reading have focused on extreme orthographies, and much less is known about what happens in intermediate regions of orthographic depth. For example, does DYS in an orthography of intermediate depth manifest itself by low accuracy and speed for non-word reading, as in English, or does it conform more to the transparent model with high disfluency? Whether reading strategies used by dyslexic readers in intermediate orthographies are as flexible as strategies used by normal readers (see, for example, Lima \& Castro, 2010; Ziegler, Jacobs, \& Stone, 1996) is also not clear. In a preliminary naming study, Sucena, Castro and Seymour (2009) observed that DYS in Portuguese-speakers does not preclude the development of decoding abilities at the level of normal beginning readers, but the development of the orthographic lexicon is impaired. Likewise, studies with French-speakers suggest that orthographic skills are not firmly established in children (Sprenger-Charolles, Colé, Kipffer-Piquard, Pinton, \& Billard, 2009) and adults with DYS (Martin et al., 20I0).

\section{The Current Study}

Considering the Portuguese language an orthography of intermediate depth (Seymour, Aro, \& Erskine, 2003), the aim of the present study was to investigate whether, and to what extent, children with DYS employ lexical orthographic reading. The effect of lexicality, word frequency and stimulus length was investigated during a visual lexical decision task comparing children with DYS with normal readers. Up until now, most of the studies on lexical and sublexical processing in impaired reading have employed word-naming tasks. These tasks require the reader to activate and produce the phonology of a word and then may be subject to greater influences of phonological decoding (we know that children with DYS have problems with this); these potential confounding effects were avoided here by using a visual lexical decision paradigm.

When performing lexical decisions, subjects are expected to primarily rely on lexical search (including children; van den Boer, de Jong, \& Meeteren, 2012; Schmalz, Marinus, \& Castles, 20I2), with the lexicon being searched serially in the order of word frequency (Coltheart et al., 200I). It was, therefore, expected that Portuguese-speaking normal readers would respond faster to high-frequency words than to low-frequency words and pseudowords. Additionally, and in-line with previous lexical decision studies (Di Filippo et al., 2006; Martens \& Jong, 2006), it was expected that normal readers would show a length effect to pseudowords only. Conversely, if the lexical route is less efficient for children with DYS, then frequency effects should be smaller in this group (i.e. result in a frequency by group interaction). In this case, children with DYS might also be expected to rely more heavily on a phonological decoding strategy (albeit poorly), causing an effect of length for both words and pseudowords, unlike controls. Finally, it was predicted that a strong lexicality effect would characterize the performance of Portuguese-speaking dyslexics, at least in terms of response speed, as shown in transparent orthographies. 


\section{METHOD}

\section{Participants}

Informed consent was obtained from all the parents of participants in compliance with the Helsinki Declaration. Eighteen children with a formal diagnosis of DYS (I I men and seven women; mean age $[ \pm s t d]=\mid 20[ \pm \mid 2.7]$ months) were recruited through private clinics specialized for children with special needs. They were all native speakers of Portuguese and attended public schools in the 3rd, 4th and 5 th grades. The inclusion criteria for the participants with DYS were as follows: normal-range intelligence measured by the Wechsler Intelligence Scale for Children (Wechsler, 2006); reading abilities significantly below mean grade level; and absence of neurological, emotional or attentional problems. The individual's reading achievement was assessed through the time-limited reading aloud test, which was adapted for the Portuguese population from the Differential Diagnosis DYS Battery (Blomert \& Vaessen, 2009). The reading test contained three subtasks of high-frequency and low-frequency words and pseudowords (half a minute for each subtask); reading speed was taken as the number of correct items read per second. The test-retest reliability was .9l. Scores were converted into z-scores with reference to normative data, which was collected in a largescale study with 820 Portuguese children (Reis et al., 20I3). Only those subjects who had reading speed scores at least I.5 standard deviation (SD) below the grade mean of the normative sample were included in the dyslexic group. The dyslexic group was matched by chronological age' with 19 normally developing children ( 13 boys and six girls; mean age $[ \pm s t d]=\mid 17[ \pm \mid 2.2]$ months), who were 3rd, 4 th and 5 th graders. All of the controls were classified by their teachers as average pupils, had intelligence scores in the normal range (Wechsler Intelligence Scale for Children) and reading scores within or above average. As expected, participants with DYS significantly differed from age-matched controls $(C A ; p<.00 \mathrm{I})$ in terms of Differential Diagnosis DYS Battery reading norm scores. All children were further assessed for phonological skills, using two traditional phonological awareness tasks: phoneme deletion and phoneme substitution. Both tasks are standardized for Portuguese school age children (Albuquerque, Simões, \& Martins, 20 I I). Dyslexics' norm scores were lower than those of the control group $(p<.00 \mathrm{I})$. Descriptive statistics for each reading group are given in Table $\mathrm{I}$.

\section{Visual Lexical Decision Task}

Stimulus material

For the lexical decision task, 64 words were selected from a Portuguese lexical database (Faísca, Bramão, Araújo, Pacheco, \& Reis, 2006), according to word frequency (high versus low) and length (two versus three syllables). Half of the high-frequency and low-frequency words had two syllables (4-5 letters; 'short' items), and the remaining words had three syllables (6-7 letters; 'long' items). Frequency of the first syllable and the number of phonological neighbours were controlled ( $p>.05$ across all conditions, for all variables). Each word was transformed into a pseudoword by changing the second and, in case of three-syllable items, also the third syllable. To accomplish this, we swapped syllables between different words based on the criterion of changing the first consonant and keeping the 
Table I. Mean age, IQ (Wechsler Intelligence Scale for Children - WISC III), vocabulary (WISC-III), scores on the reading level test (items/sec), and scores on the Phoneme deletion (Phon. Del.) and Phoneme substitution (Phon. Subst.) tasks (corrects/máx.19), for children with dyslexia and controls

\begin{tabular}{|c|c|c|c|c|}
\hline & $\begin{array}{l}\text { Dyslexics } \\
\text { Raw score }\end{array}$ & Standardized score & $\begin{array}{l}\text { Age controls } \\
\text { Raw score }\end{array}$ & Standardized score \\
\hline IQ full-scale & n.a. & $98.4(9.3)$ & n.a. & $103.5(11.2)$ \\
\hline $\begin{array}{l}\text { Vocabulary } \\
\text { Reading }\end{array}$ & n.a. & I0.I (3.0) & n.a. & II.4 (3.4) \\
\hline Words & $.37(.2 \mathrm{I})$ & $4.73(\mathrm{I} .78)$ & $.99(.20)$ & $10.42(1.88)$ \\
\hline Pseudowords & $.30(.19)$ & $4.72(2.10)$ & $.75(.18)$ & $10.20(2.28)$ \\
\hline Phon. Del. & n.a. & $4.5(2.7)$ & n.a. & II.I (2.I) \\
\hline Phon. Subst. & n.a. & $4.5(2.1)$ & n.a. & I2.I (2.2) \\
\hline
\end{tabular}

Note. Standard deviations are presented between parentheses. n.a. not available.

Standardized scores: IQ expressed in IQ scores (mean $=100, S D=15$ ); performance on other tasks expressed in standardized scores $($ mean $=10, S D=3)$.

original vowels (e.g. the word 'girafa' [giraffe] was changed into the pseudoword 'gidala'; see Appendix A for a full list of items).

\section{Experimental procedures}

The stimuli were randomized and displayed on a computer screen using presentation software (version 7.0; nbs.neuro-bs.com/presentation). Words and pseudowords were presented in lower case ('arial', font size 60, and black font on white background). All stimuli were presented at eye-level at the centre of the screen, $\sim 60 \mathrm{~cm}$ away from the subject and ranged from $2.0^{\circ}$ to $3.7^{\circ}$ of visual angle. Each trial began with a fixation cross presented in the centre of the screen for I second, after which the stimulus was presented until the participant provided a response. Participants were instructed to determine whether the item corresponded to a real word or to a false word and to use their finger to press a designated button on a response box. Accuracy and RTs were automatically recorded. Practice items were given to adequately familiarize participants with the task.

\section{Data Analysis}

The mean percentage accuracy and the mean RTs for high-frequency and lowfrequency words and pseudowords of different lengths, for the two reading groups, are displayed in Table 2. Mean RT scores were calculated for correct trials only (78\% for DYS and $94 \%$ for CA). Latencies were also considered invalid when the response was premature $(<325 \mathrm{~ms})$ or when the response deviated more than 3 SDs from a child's experimental condition mean ( $0.77 \%$ for DYS and $1.55 \%$ for CA). The significant differences for the different stimulus conditions and for each group were tested with repeated measures ANOVAs, including the stimulus type [high-frequency versus low-frequency words versus pseudowords] and length [short versus long] as within-subject factors and the group as a between-subject factor [DYS versus CA]. The degrees of freedom of the stimulus type effect were split into two orthogonal contrasts: a lexicality effect (words versus pseudowords) and a frequency 
Table 2. Mean response times (ms) and accuracy percentages for high and low-frequency words and pseudowords of two and three syllables in lexical decision, for children with dyslexia and controls

\begin{tabular}{|c|c|c|c|c|}
\hline \multirow{2}{*}{ Reading group } & \multicolumn{2}{|c|}{ Two syllables } & \multicolumn{2}{|c|}{ Three syllables } \\
\hline & Speed & Accuracy & Speed & Accuracy \\
\hline \multicolumn{5}{|l|}{ Dyslexics } \\
\hline High-frequency words & $2850(\mid 127)$ & $90(\mid 4.30)$ & $3554(1824)$ & $90(13.06)$ \\
\hline Low-frequency words & $3724(1719)$ & $64(16.96)$ & $4238(1842)$ & $72(16.70)$ \\
\hline Pseudowords & $4739(1761)$ & $74(15.84)$ & $5294(2505)$ & $82(16.74)$ \\
\hline \multicolumn{5}{|l|}{ Age-matched controls } \\
\hline High-frequency words & II 36 (225) & $98(3.54)$ & II7| (219) & $99(3.35)$ \\
\hline Low-frequency words & $1372(376)$ & $78(9.89)$ & $|40|(290)$ & $90(9.46)$ \\
\hline Pseudowords & I894 (38I) & $95(5.03)$ & $2204(616)$ & $96(4.58)$ \\
\hline
\end{tabular}

Note. Standard deviations are presented between parentheses.

effect (high-frequency versus low-frequency words), both with one degree of freedom. Because the present data were not normally distributed (RTs: Shapiro-Wilk normality test $W=.85, p<.001$; accuracy: $W=.88, p<.001$ ) and the variance differed substantially across conditions as well as between reading groups (as can be seen in Table 2), the parametric statistical analyses were complemented with non-parametric analyses. Friedman test was used to test the main effect of lexicality, frequency and length. Mann-Whitney test $(U)$ was used to compare the groups' performance. Supplementing parametric analyses with non-parametric analyses to ensure validity has already been used in previous studies on DYS (e.g. Heiervang, Stevenson, \& Hugdahl, 2002; Martin et al., 2010).

Finally, to test if the interactions between group and experimental manipulations were independent of the spurious effect of general performance differences (overadditivity effect), we re-analyzed the data using the data transformations proposed by Faust and colleagues (1999), that is, raw data (RT) was standardized with reference to subjects' individual means. Non-parametric tests were not applied to the overadditivity analysis, because this analysis involves just a rescaling of within-subject raw data and, consequently, not affect the rank transformations used by non-parametric procedures.

\section{RESULTS}

Global accuracy and speed of lexical decisions

There was a significant difference in the performance of lexical decision among the two reading groups, both for $\mathrm{RTs}\left(F(I, 36)=47.53, p<.00 \mathrm{I}\right.$, partial $\eta^{2}=.57$; $U=5.0, p<.00 \mathrm{I})$ and errors $\left(F(I, 36)=33.89, p<.00 \mathrm{I}\right.$, partial $\eta^{2}=.48 ; U=I I .5$, $p<.001)$. The children with DYS were generally slower than the CA participants and also made relatively more errors.

Lexicality and frequency effects

The global ANOVA showed a significant effect of stimulus type both on RTs ( $F$ $(2,72)=38.47, p<.00$ I, partial $\eta^{2}=.52$; Friedman test $\left.\chi^{2}(2)=64.47, p<.00 \mathrm{I}\right)$ and on errors $\left(F(2,72)=29.07, p<.001\right.$, partial $\eta^{2}=.45$; Friedman test 
$\left.\chi^{2}(2)=49.91, p<.00 I\right)$. Contrast analyses showed a significant effect of lexicality on RTs $\left(F(1,36)=47.22, p<.00 \mathrm{I}\right.$, partial $\eta^{2}=.57$; Friedman test $\left.\chi^{2}(I)=34 . I I, p<.00 I\right)$. This main effect indicates that words were responded faster than pseudowords. The interaction between lexicality and group approached significance $\left(F(I, 36)=4.05, p=.052\right.$, partial $\left.\eta^{2}=.10\right)$, indicating a greater difference between word and pseudoword RTs in the DYS group than in the CA group. In addition, there was a main effect of frequency on both RTs $\left(F(I, 36)=17.70, p<.00 \mathrm{I}\right.$, partial $\eta^{2}=.33$; Friedman test $\left.\chi^{2}(I)=26.95, p<.00 \mathrm{I}\right)$ and errors $\left(F(1,36)=73.36, \quad p<.00 \mathrm{I}\right.$, partial $\eta^{2}=.67$; Friedman test $\left.\chi^{2}(I)=34 . I I, p<.00 I\right)$, reflecting the fact that subjects responded faster and more accurately to high-frequency words than to low-frequency words. The effect of frequency on RTs was modulated by the factor group, as indicated by the interaction group by frequency $\left(F(I, 36)=5.15, p=.029\right.$, partial $\eta^{2}=.13$ ). The CA responses were faster to high-frequency words than to low-frequency words; this difference was true to a larger extent in DYS.

\section{Length effects}

The global ANOVA showed a significant main effect of length on both RTs ( $F$ $(I, 36)=31.58, p<.00 \mathrm{I}$, partial $\eta^{2}=.47$; Friedman test $\left.\chi^{2}(I)=20.63, p<.00 \mathrm{I}\right)$ and errors $\left(F(1,36)=37.58, \quad p<.00 \mathrm{I}\right.$, partial $\eta^{2}=.5 \mathrm{I}$; Friedman test $\left.\chi^{2}(I)=18.78, p<.00 I\right)$. The children responded faster and more accurately to short than to long items. The effect of length on response speed was modulated by the factor group $\left(F(I, 36)=13.39, p=.00 \mathrm{I}\right.$, partial $\left.\eta^{2}=.27\right)$, as length affected DYS more than CA. Follow-up simple analyses also revealed that although the effect of length was limited to pseudowords in normal readers $(F(I, I 8)=10.0$, $p=.005$, partial $\eta^{2}=.36$ ), length affected both words and pseudowords in dyslexic readers $\left(F(I, \mid 8)=.01, p=.9 I\right.$, partial $\left.\eta^{2}=.00\right)$. Additionally, a significant interaction between frequency and length was obtained for errors $\left(F(I, 36)=26.7 I, p<.00 I\right.$, partial $\left.\eta^{2}=.43\right)$, indicating a length effect for low-frequency but not for high-frequency words. No other interaction effects were observed, including the interaction between length and lexicality $(F$ 's $<I)$.

\section{Overadditivity effects}

Response times raw data were transformed into z-scores by taking each individual's condition means, subtracting their overall mean and dividing it by the SD of their condition means (Faust et al., 1999). An ANOVA was performed on these $z$-scores values.

Because of $z$-score transformation, the main effect of the between-subject factor (Group) is, by definition, null in this ANOVA. The main effects of lexicality $\left(F(I, 36)=408.77, p<.00 I\right.$, partial $\left.\eta^{2}=.92\right)$ and frequency $(F(I, 36)=53.25$, $p<.00 \mathrm{I}$, partial $\eta^{2}=.60$ ) were significant, indicating higher $z$-values (i.e. faster RTs) for words than for pseudowords and for high-frequency than for low-frequency words. The main effect of length $\left(F(I, 36)=38.07, p<.00 \mathrm{I}\right.$, partial $\left.\eta^{2}=.5 \mathrm{I}\right)$ confirmed that the children had faster RTs for short than long stimuli. More importantly, when data were transformed into $z$-values, the interaction frequency by group disappeared, $p=.1 \mathrm{II}$, thus indicating that the presence of this interaction in raw RTs was due to an overadditivity effect, that is, because DYS had generally slower RTs in lexical decision. However, the interaction between lexicality and group remained near significance, $F(I, 36)=3.92, p=.056$, partial $\eta^{2}=.10$, and the 
length by group interaction was still significant, $F(I, 36)=4.26, p=.046$, partial $\eta^{2}=.1 \mathrm{l}$. The group by lexicality by length interaction was marginally significant, $F(I, 36)=3.88, p=.057$, partial $\eta^{2}=.10$. Children with DYS showed a significant difference between short and long stimuli for both words and pseudowords, whereas CA showed an effect of length only for pseudowords. Mean z-scores are presented separately in Figure I for the dyslexics and CA as a function of lexicality and length.

\section{DISCUSSION}

This study provided evidence that visual lexical decision tasks effectively capture the dyslexic deficit, as previously demonstrated for opaque (English: Milne, Nicholson, \& Corballis, 2003) and transparent orthographies (Italian: Di Filippo et al., 2006; Marinelli, Angelelli, Di Filippo, \& Zoccolotti, 20I I; Dutch: Martens \& Jong, 2006). Overall, lexical decisions were less accurate and significantly slower in dyslexic children than in their normal reading-peers, and both groups were affected by the experimental manipulations in a qualitatively different manner.

The results of the present study showed a striking length effect for children with DYS. As predicted, the increase in dyslexics' RT due to item length was observed both for words (high-frequency and low-frequency) and pseudowords. Critically, the overadditivity analysis confirmed this pattern, thus indicating that stimulus length plays a critical role in modulating the impaired dyslexics' performance. The length effect allows us to quantify serial processes in word reading (Coltheart et al., 200I), and the present results indicate that regardless of the stimulus status, Portuguese-speaking dyslexic children predominantly adopt a low-level phonological decoding procedure (even if the efficiency of this procedure is itself suboptimal). Notably, dyslexics' reliance on such a strategy occurs even in the context of a visual lexical decision task that favours processing along the lexical route (van den Boer et al., 2012; Schmalz et al., 2012). Similar results were obtained in transparent orthographies using both lexical decision (Di Filippo et al., 2006; Juphard, Carbonnel, \& Valdois, 2004; Martens \& Jong, 2006) and naming tasks (Davies, Rodríguez-Ferreiro, Suárez, \& Cuetos, 2012;

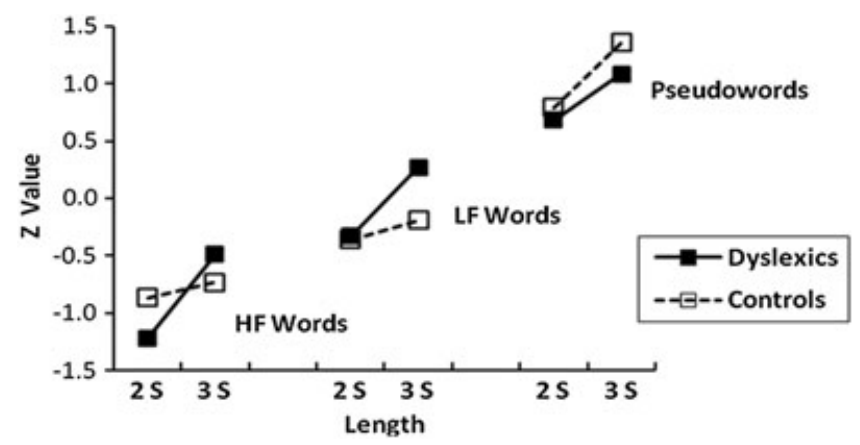

Figure I. Mean z-values of dyslexic readers and control readers as a function of stimulus length ( $2 \mathrm{~S}$, two syllables; $3 \mathrm{~S}$, three syllables) and lexicality (HF words, high-frequency words; LF words, low-frequency words). Positive and negative values indicate fast and slow response times, respectively. 
Paizi, Zoccolotti, \& Burani, 20I I; Zoccolotti et al., 2005). The data are also compatible with word-naming studies in English-speaking dyslexics (Ziegler et al., 2003) but, to our knowledge, no study has addressed the length effect on dyslexics' lexical decisions. Possibly, the effect of length on lexical decision making would be less pronounced in English-speaking samples, assuming that reading in transparent orthographies relies more heavily on a grapheme-to-phoneme decoding strategy, whereas children learning to read in English must develop recoding strategies at larger grain sizes (cf. Ziegler \& Goswami, 2005; Ziegler, Perry, Jacobs, \& Braun, 200I).

In contrast to the dyslexic readers, proficient readers in this study were only affected by the length of pseudowords, in agreement with previous lexical decision studies (Di Filippo et al., 2006; Martens \& Jong, 2006). Therefore, it seems that during lexical decisions, children rely on orthographic lexical retrieval when presented with words (similar to adults), but for unknown stimuli such as pseudowords, children adopt a more 'conservative' strategy, basing their decisions also on sublexical decoding to obtain a second pass confirmation. In other words, we argue that stimulus familiarity played a role in the decision strategy of our normally developing sample, which seems to have the capacity to modify the resources utilized in response to the task demands, similar to Portuguese-speaking adults (Lima \& Castro, 20I0). Conversely, children with DYS appear not to be as flexible in switching strategies based on lexical information.

One reason for this pattern of results might be that Portuguese children with DYS preferentially use the decoding procedure because they struggle to process orthographic inputs as a whole, the way control readers do. Indeed, data indicate that dyslexic children's performance was influenced by length even on words that are assumed to be well-established in the orthographic lexicon as high-frequency words (Marinelli et al., 2009). This further suggests a suboptimal functioning of orthographic lexical processing; otherwise, it would be expected that dyslexics were less affected by stimulus length, at least for this type of stimuli. In a previous naming study with a similar population, Portuguese dyslexic children likewise demonstrated a developmental deficit in orthographic processing (as shown by the length and regularity effects; Sucena et al., 2009). Recent naming studies conducted in German and Dutch languages (e.g. Bergmann \& Wimmer, 2008; Marinus \& de Jong, 2010) also support the present view. Furthermore, in a lexical decision study with English readers, Schmalz and colleagues (20I2) concluded that 'children with weak orthographic lexicons (...) are forced to rely on their-albeit poor-phonological decoding for the majority of words' (p.7). So, to some extent, it seems that the observed results support the hypothesis put forward by Bosse and colleagues who proposed that impaired lexical orthographic processing could be one of the causes of reading disorder regardless of the transparency of the language learned (Bosse, Tainturier, \& Valdois, 2007).

An important note to add here is that the present results do not indicate that dyslexics were unable to use the lexical route to a certain extent. An indicator of the contribution of lexical access to reading is the word frequency effect (Coltheart et al., 200I), and in this study we did find a reliable effect both for dyslexics and controls, with faster decisions for high-frequency than for lowfrequency words. This result is consistent with those obtained on other performance measures (e.g. in Spanish, Davies et al., 2012; in Italian, Paizi, 
Zoccolotti, et al., 20I I), although it has not been confirmed that the frequency effect was actually larger for children with DYS than for controls, as sometimes reported (Barca et al., 2006; Ziegler et al., 2003). However, it is possible that the results of these studies reflect dyslexics slower overall RTs (i.e. a 'spurious' interaction) because the interaction effect of group by frequency disappeared in the present z-score analysis. Thus, the presence of a frequency effect in the Portuguese-speaking dyslexics suggests that orthographic lexical traces have been encoded in the orthographic memory and reflects the fact that these readers have still been able to access and retrieve them. Even if dyslexic children also draw on the lexical procedure, it may be that their orthographic lexical entries are less established in the orthographic lexicon and take longer to become activated, thus allowing the output of phonological decoding to interfere with their responding. This would explain why it was found a length effect independent of word frequency in these readers.

To what extent the inefficiency of the lexical orthographic routine has a phonological locus is unclear. According to the self-teaching hypothesis (Share, 1995), the sublexical procedure is the bootstrapping procedure upon which lexical reading develops, which implies that a lexical deficit would only be a consequence of a phonological/decoding problem. Notwithstanding this possibility, we believe that some results in this study suggest that the nature of lexical orthographic problems in an intermediate orthography such as Portuguese is more complicated. First, when differences in performance deficits of the dyslexic participants compared with the CA were quantified on each type of item, it was observed that the dyslexics' pseudoword performance was not impaired more than the high-frequency word performance (Cohen's $d>2$ for both types of items). Second, no significant correlation was found between dyslexics' results on the phonological awareness tasks and their performance on lexical decision speed (Pearson's $r=-.207, p=.396$ ). Possibly, these results reflect the fact that when the phonological demands are reduced (as is the case with orthographies more consistent than English), phonological awareness is relatively less important in reading development (e.g. Landerl \& Wimmer, 2008).

Finally, when considering the influence of lexicality on lexical decisions, the results of this study showed a greater lexicality effect in Portuguese-speaking dyslexics than in controls, which was expressed both in the raw data and z-transformed data. This is suggestive of a deficit in the use of the phonological decoding procedure, different from what Di Filippo et al. (2006, in a lexical decision task) and Zoccolotti et al. (2008, in a naming task) reported for Italian, that is, the lexicality effect was due entirely to an overadditivity effect. Yet, Portuguese-speaking dyslexics' decoding problems are mainly expressed in terms of response speed, not in both accuracy and speed, as often reported for English-speakers (e.g. Rack et al., 1992).

To summarize, the current results appear to suggest that, in an orthography of intermediate depth, children with DYS are not as flexible as CA in switching from sublexical decoding to lexical orthographic strategies, according to stimulus demands. A possible explanation is that children with DYS predominantly adopt a decoding strategy, despite their lack of accurate phonological knowledge, likely because they cannot rely on an efficient lexical orthographic procedure. Thus, in an intermediate orthography, both lexical and sublexical procedures seem not to work normally in DYS; however, 
one limitation of the present study is that it investigated a relatively small sample of dyslexic children and, therefore, conclusions based on group differences need to be interpreted cautiously.

\section{APPENDIX A:}

EXPERIMENTAL MATERIALS

\begin{tabular}{|c|c|c|c|}
\hline \multicolumn{2}{|c|}{ Words } & \multicolumn{2}{|c|}{ Pseudowords } \\
\hline High-frequency & Low-frequency & High base word frequency & Low base word frequency \\
\hline Copo (glass) & Cova (hole) & Cogo & Coja \\
\hline Mesa (table) & Face (face) & Meba & Fave \\
\hline Dedo (finger) & Cano (tube) & Deno & Cado \\
\hline Medo (fear) & Cave (basement) & Meno & Cace \\
\hline Calor (heat) & Canil (kennel) & Camor & Catil \\
\hline Pedra (stone) & Petiz (kid) & Pebra & Peliz \\
\hline Cabra (goat) & Cofre (safe) & Catra & Copre \\
\hline Fumo (smoke) & Bule (teapot) & Fudo & Bude \\
\hline Dado (dado) & Cera (wax) & Dalo & Ceja \\
\hline Doce (sweet) & Bife (steak) & Dole & Bite \\
\hline Bico (beak) & Juba (mane) & Bido & Juva \\
\hline Ninho (nest) & Talho (butcher) & Nilho & Tasso \\
\hline Feliz (happy) & Dedal (thimble) & Fetiz & Denal \\
\hline Sinal (signal) & Cetim (satin) & Sidal & Cedim \\
\hline Burro (mule) & Rumor (rumor) & Bulho & Rulor \\
\hline Papel (paper) & Febre (fever) & Patel & Fefre \\
\hline Comida (food) & Sineta (handbell) & Cozita & Sileda \\
\hline Cabeça (head) & Cigano (gypsy) & Caneda & Cibaco \\
\hline Cavalo (horse) & Gorila (gorilla) & Carado & Gopira \\
\hline Palhaço (clown) & Capela (chapel) & Panhapo & Canesa \\
\hline Caracol (snail) & Debate (debate) & Cavabol & Derafe \\
\hline Devagar (slow) & Coruja (owl) & Degadar & Coluta \\
\hline Corrida (race) & Petisco (tidbit) & Colhita & Pexisto \\
\hline Cozinha (kitchen) & Capital (capital) & Comirra & Caridal \\
\hline Janela (window) & Paladar (tast) & Jarefa & Padagar \\
\hline Cereja (cherry) & Repolho (cabbage) & Cebeta & Redorro \\
\hline Girafa (giraffe) & Medalha (medal) & Gidala & Melanha \\
\hline Gelado (ice-cream) & Cevada (barley) & Gevaço & Cefata \\
\hline Cidade (city) & Muleta (crutch) & Cilate & Mupela \\
\hline Cigarra (grig) & Pimento (pepper) & Civalha & Pifenda \\
\hline Gigante (giant) & Cimento (cement) & Gipance & Citenco \\
\hline Barulho (noise) & Taxista (cabby) & Badunho & Tatisla \\
\hline
\end{tabular}

\section{ACKNOWLEDGEMENTS}

This work was supported by the grants SFRH/BD/28488/2006, PTDC/PSI/64920/2006, PTDC/PSI-PCO/II0734/2009, and IBB/CBME, LA, FEDER/POCI 2010 from Fundação para a Ciência e Tecnologia. The authors would like to thank three anonymous reviewers for their very helpful comments on the manuscript. 


\section{NOTE}

I. In a previous study, Zoccolotti and colleagues (2008) proposed that utilizing models such as the rate-and-amount model (Faust, Balota, Spieler, \& Ferraro, 1999) in chronologically matched samples might be more powerful than the reading-age match method in isolating global components of performance from the influence of task-specific deficits. Because, in the present study, we performed z-transformed score analyses as suggested by Faust and colleagues, we chose to use a chronologically matched design (see also van den Broeck \& Geudens, 2012, for a recent discussion on the limits of the reading-age match approach).

\section{REFERENCES}

Albuquerque, C. P., Simões, M. R., \& Martins, C. (20II). Testes de consciência fonológica da bateria de avaliação neuropsicológica de Coimbra: Estudos de precisão e validade [Phonological awareness tests of Coimbra's neuropsychological assessment battery: Reliability and validity studies]. Revista Ibero-Americana de Diagnóstico e Avaliação Psicoló gica, 29(I), 5 I-76.

Barca, L., Burani, C., Di Filippo, G., \& Zoccolotti, P. (2006). Italian developmental dyslexic and proficient readers: Where are the differences? Brain and Language, 98, 347-35I. DOI: 10.1016/j. bandl.2006.05.00I

Beech, J. R., \& Awaida, M. (1992). Lexical and nonlexical routes: A comparison between normally achieving and poor readers. Journal of Learning Disabilities, 25(3), 196-206. DOI: I0.1177/002221949202500307

Bergmann, J., \& Wimmer, H. (2008). A dual-route perspective on poor reading in a regular orthography: Evidence from phonological and orthographic lexical decisions. Cognitive Neuropsychology, 25(5), 653-676. DOI: 10.1080/0264329080222I404

Blomert, L., \& Vaessen, A. (2009). Differentiaal diagnostiek van dyslexie; Cognitieve analyse van lezen en spellen (dyslexia differential diagnosis; cognitive analysis of reading and spelling). Amsterdam: Boom test publishers B. V.

van den Boer, M., de Jong, P. F., \& Meeteren, M. M. H (20/2). Lexical decisión in children: Sublexical processing or lexical search? The Quarterly Journal of Experimental Psychology, 65(6), 1214-1228. DOI: $10.1080 / 17470218.2011 .652136$

Bosse, M. L., Tainturier, M. J., \& Valdois, S. (2007) Developmental dyslexia: the visual attention span deficit hypothesis. Cognition, 104, 198-230. DOI: 10.1016/j.cognition.2006.05.009

Castles, A., Bates, T., Coltheart, M., Luciano, M., \& Martin, N. G. (2006). Cognitive modelling and the behaviour genetics of reading. Journal of Research in Reading, 29(1), 92-103. DOI: 10.1 III/j. I 467-9817.2006.00294.x

Coltheart, M. (2007). Modeling reading: The dual-route approach. In M. J. Snowling, \& C. Hulme (Eds.), The science of reading: A handbook (pp. 6-23). UK: Blackwell Publishing.

Coltheart, M., Rastle, K., Perry, C., Langdon, R., \& Ziegler, J. C. (200I). DRC: A dual route cascaded model of visual word recognition and reading aloud. Psychological Review, 108(I), 204-256. DOI: 10.1037//0033-295X.108.1.204

Davies, R., Rodríguez-Ferreiro, J., Suárez, P., \& Cuetos, F. (2012). Lexical and sub-lexical effects on accuracy, reaction time and response duration: Impaired and typical word and pseudoword reading in a transparent orthography. Reading and Writing, I-|8. DOI: 10.1007/s | | |45-0I2-9388-I

De Luca, M., Barca, L., Burani, C., \& Zoccolotti, P. (2008). The effect of word length and other sublexical, lexical, and semantic variables on developmental reading deficits. Cognitive and Behavioral Neurology, 2I, 227-235. DOI: I0.1097/WNN.0b013e318190dI62

De Luca, M., Borrelli, M., Judica, A., Spinelli, D., \& Zoccolotti, P. (2002). Reading words and pseudowords: An eye movement study of developmental dyslexia. Brain and Language, 80, 6I7-626. DOI: 10.1006/brln.200I.2637 
Di Filippo, G., De Luca, M., Judica, A., Spinelli, D., \& Zoccolotti, P. (2006). Lexicality and stimulus length effects in Italian dyslexics: Role of the overadditivity effect. Child Neuropsychology, 12, I4I-|49. DOI: 10.1080/0929704050034657|

Faísca, L., Bramão, I., Araújo, S., Pacheco, A., \& Reis, A. (2006, November). Corpus lingulístico constituído a partir de manuais escolares [Linguistic corpus from children textbooks]. Paper presented at the VI Simpósio Nacional de Investigação em Psicologia, Universidade de Évora.

Faust, M. E., Balota, D. A., Spieler, D. H., \& Ferraro, F. R. (1999). Individual differences in informationprocessing rate and amount: Implications for group differences in response latency. Psychological Bulletin, 125, 777-799. DOI: 10.1037/0033-2909.125.6.777

Gonzalez, J. E. J., \& Valle, I. H. (2000 ). Word identification and reading disorders in the Spanish language. Journal of Learning Disabilities, 33(I), 44-60. DOI: 10.1 I77/002221940003300I08

Grainger, J., Bouttevin, S., Truc, C., Bastien, M., \& Ziegler, J. (2003). Word superiority, pseudoword superiority, and learning to read: A comparison of dyslexic and normal readers. Brain and Language, 87, 432-440. DOI: 10.1016/S0093-934X(03)00I45-7

Harm, M. W., \& Seidenberg, M. S. (1999). Phonology, reading acquisition, and dyslexia: Insights from connectionist models. Psychological Review, 106(3), 49I-528. DOI: 10.1037/0033-295X.106.3.49।

Hawelka, S., Gagl, B., \& Wimmer, H. (2010). A dual-route perspective on eye movements of dyslexic readers. Cognition, II5, 367-379. DOI: 10.1016/j.cognition.2009.11.004

Heiervang, E., Stevenson, J., \& Hugdahl, K. (2002). Auditory processing in children with dyslexia. Journal of Child Psychology and Psychiatry, 43(7), 93 I-938. DOI: I0.I I I // 4699-76I0.00097

ljzendoorn, M. H., \& Bus, A. G. (1994). Meta-analytic confirmation of the nonword reading deficit in developmental dyslexia. Reading Research Quarterly, 29(3), 266-275. DOI: 10.2307/747877

de Jong, P. F., \& van der Leij, A. (1999). Specific contributions of phonological abilities to early reading acquisition: Results from a Dutch latent variable longitudinal study. Journal of Educational Psychology, 9I(3), 450-476. DOI: 10.1037/0022-0663.91.3.450

Judica, A., De Luca, M., Spinelli, D., \& Zoccolotti, P. (2002). Training of developmental surface dyslexia improves reading performance and shortens eye fixation duration in reading. Neuropsychological Rehabilitation, 12, 177-19. DOI: 10.1080/09602010244000002

Juphard, A., Carbonnel, S., \& Valdois, S. (2004). Length effect in reading and lexical decision: evidence from skilled readers and a developmental dyslexic participant. Brain and Cognition, 55, 332-340.04. DOI: 10.1016/j.bandc.2004.02.035

Landerl, K., \& Wimmer, H. (2008). Development of word reading fluency and spelling in a consistent orthography: An 8-year follow-up. Journal of Educational Psychology, 100(I), 150-161. DOI: 10.1037/0022-0663.100.1.150

Landerl, K., Wimmer, H., \& Frith, U. (1997). The impact of orthographic consistency on dyslexia: A German-English comparison. Cognition, 63, 315-334. DOI: http://dx.doi.org/I0.1016/S00 10-0277(97)00005-X

Lima, C. F., \& Castro, S. L. (2010). Reading strategies in orthographies of intermediate depth are flexible: Modulation of length effects in Portuguese. European Journal of Cognitive Psychology, 22(2), |90-2I5. DOI: 10.1080/0954|440902750|45

Marinelli, C. V., Angelelli, P., Notarnicola, A., \& Luzzatti, C. (2009). Do Italian dyslexic children use the lexical reading route efficiently? An orthographic judgment task. Reading and Writing, 22, 333-35I. DOI: 10.1007/s |||45-008-9||8-x

Marinellia, C. V., Angelelli, P., Di Filippo, G., \& Zoccolottia, P. (20I I). Is developmental dyslexia modality specific? A visual-auditory comparison of Italian dyslexics. Neuropsychologia, 49, 17I8-1729. DOI: 10.1016/j.neuropsychologia.2011.02.050

Marinus, E., \& de Jong, P. F. (2010). Size does not matter, frequency does: Sensitivity to orthographic neighbors in normal and dyslexic readers. Journal of Experimental Child Psychology, 106, 129-144. DOI: 10.1016/j.jecp.2010.01.004

Martens, V. E. G., \& Jong, P. F. (2006). The effect of word length on lexical decision in dyslexic and normal reading children. Brain and Language, 98, I40-149. DOI: 10.1016/j.bandl.2006.04.003

Martin, J., Colé, P., Leuwers, C., Casalis, S., Zorman, M., \& Sprenger-Charolles, L. (2010) Reading in French-speaking adults with dyslexia. Annals of Dyslexia, 60, 238-264. DOI: |0.1007/s I |88I-010-0043-8 
Metsala, J. L., Stanovich, K. E., \& Brown, G. D. A. (1998). Regularity effects and the phonological deficit model of reading disabilities: A meta-analytic review. Journal of Educational Psychology, 90(2), 279-293. DOI: 10.1037/0022-0663.90.2.279

Milne, R. D., Nicholson, T., \& Corballis, M. C. (2003). Lexical access and phonological decoding in adult dyslexic subtypes. Neuropsychology, I 7(3), 362-368. DOI: I0.1037/0894-4I05.17.3.362

Paizi, D., Burani, C., De Luca, M., \& Zoccolotti, P. (20II). List context manipulation reveals orthographic deficits in Italian readers with developmental dyslexia. Child Neuropsychology, I7(5), 459-482. DOI: 10.1080/09297049.2010.55II87

Paizi, D., Zoccolotti, P., \& Burani, C. (20II). Lexical stress assignment in Italian developmental dyslexia. Reading and Writing, 24, 443-46I. DOI: 10.1007/s I I 145-010-9236-0

Rack, J. P., Snowling, M. J., \& Olson, R. K. (1992). The nonword reading deficit in developmental dyslexia: A review. Reading Research Quarterly, 27(1), 29-53.

Ramus, F., Rosen, S., Dakin, S. C., Day, B. L., Castellote, J. M., White, S., et al. (2003). Theories of developmental dyslexia: Insights from a multiple case study of dyslexic adults. Brain, I26, 84I-865. DOI: 10.1093/brain/awg076

Reis, A., Castro, S. L., Inácio, F., Pacheco, A., Araújo, S., Santos, M., et al. (2013). Versão Portuguesa da Bateria 3DM para avaliação da leitura e da escrita [3DM Portuguese version to assess reading and spelling skills]. Manuscript in preparation.

Schmalz, X., Marinus, E., \& Castles, A. (2012). Phonological decoding or direct access? Regularity effects in lexical decisions of grade 3 and 4 children. The Quarterly Journal of Experimental Psychology, 00(0), I-9. http://dx.doi.org//0.1080/174702/8.2012.7II843

Seymour, P. H. K., Aro, M., \& Erskine, J. M. (2003). Foundation literacy acquisition in European orthographies. British Journal of Psychology, 94, 143-174. DOI: I0.1348/0007| 260332 I66I859

Share, D. L. (1995). Phonological recoding and self-teaching: sine qua non of reading acquisition. Cognition, 55, I5I-2 I8. DOI: http://dx.doi.org/I0.1016/00 I0-0277(94)00645-2

Spinelli, D., de Luca, M., di Filippo, G., Mancini, M., Martelli, M., \& Zoccolotti, P. (2005). Length effect in word naming in reading: Role of reading experience and reading deficit in Italian readers. Developmental Neuropsychology, 27, 217-235. DOI: 10.1207/s I5326942dn27022

Sprenger-Charolles, L., Colé, P., Kipffer-Piquard, A., Pinton, F., \& Billard, C. (2009). Reading and Writing, 22, 8| I-842. DOI: 10.1007/s | | |45-008-9| |7-y

Sprenger-Charolles, L., Colé, P., Lacert, P., \& Sernicales, W. (2000). On subtypes of developmental dyslexia: Evidence from processing time and accuracy scores. Canadian Journal of Experimental Psychology, 54, 87-103.

Sucena, A., Castro, S. L., \& Seymour, P. H. K. (2009). Developmental dyslexia in an orthography of intermediate depth: The case of European Portuguese. Reading and Writing, 22, 79I-810. DOI: |0.1007/s | | |45-008-9|56-4

Treiman, R. (2000). The foundations of literacy. Current Directions in Psychological Science, 9(3), 89-92. DOI: I0.IIII//467-872I.00067

Vaessen, A., Bertrand, D., Tóth, D., Csépe, V., Faísca, L., Reis, A., et al. (2010). Cognitive development of fluent word reading does not qualitatively differ between transparent and opaque orthographies. Journal of Educational Psychology, 102(4), 827-842. DOI: 10.1037/a00I9465

Van den Broeck, W., \& Geudens, A. (20I2). Old and new ways to study characteristics of reading disability: The case of the nonword-reading deficit. Cognitive Psychology, 65(3), 4I4-456. DOI: 10.1016/j.cogpsych.2012.06.003

Vellutino, F. R., Fletcher, J. M., Snowling, M. J., \& Scanlon, D. M. (2004). Specific reading disability (dyslexia): What have we learned in the past four decades? Journal of Child Psychology and Psychiatry, 45(I), 2-40. DOI: I0.1046/j.002I-9630.2003.00305.x

Wechsler, D. (2006). Wechsler Intelligence Scale for Children-Third Edition (WISC-III). Lisboa: Cegoc-Tea.

Wimmer, H. (1993). Characteristics of developmental dyslexia in a regular writing system. Applied Psycholinguistics, I4, I-33. DOI: http://dx.doi.org/I0.10I7/SOI427I64000I0I 22

Wimmer, H. (1996). The nonword reading deficit in developmental dyslexia: Evidence from children learning to read German. Journal of Experimental Child Psychology, 6I, 80-90. DOI: I0.1006/jecp. 1996.0004 
Wimmer, H., \& Schurz, M. (2010). Dyslexia in regular orthographies: Manifestation and causation. Dyslexia, 16, 283-299. DOI: 10.1002/dys.4II

Ziegler, J. C., \& Goswami, U. (2005). Reading acquisition, developmental dyslexia, and skilled reading across languages: A psycholinguistic grain size theory. Psychological Bulletin, I3I(I), 3-29. DOI: 10.1037/0033-2909.131.1.3

Ziegler, J. C., Bertrand, D., Tóth, D., Csépe, V., Reis, A., Faísca, L., et al. (20I0). Orthographic depth and its impact on universal predictors of reading: $A$ cross-language investigation. Psychological Science, 2I(4), 55I-559. DOI: I0.II77/09567976/0363406

Ziegler, J. C., Castel, C., Pech-Georgel, C., George, F., Alario, F., \& Perry, C. (2008). Developmental dyslexia and the dual route model of reading: Simulating individual differences and subtypes. Cognition, 107, I5I-I78. DOI: 10.1016/j.cognition.2007.09.004

Ziegler, J. C., Jacobs, A. M., \& Stone, G. O. (1996). Statistical analysis of the bi-directional inconsistency of spelling and sound in French. Behavior Research Methods, Instruments and Computers, 28(4), 504-5 15. DOI: I0.3758/BF03200539

Ziegler, J. C., Perry, C., Jacobs, A. M., \& Braun, M. (200I). Identical words are read differently in different languages. Psychological Science, I2, 379-384. DOI: I0.1 I I I/I467-9280.00370

Ziegler, J. C., Perry, C., Ma-Wyatt, A., Ladner, D., \& Schulte-Körne, G. (2003). Developmental dyslexia in different languages: Language-specific or universal? Journal of Experimental Child Psychology, 86, 169-193. DOI: 10.1016/S0022-0965(03)00139-5

Zoccolotti, P., De Luca, M., Di Pace, E., Gasperini, F., Judica, A., \& Spinelli, D. (2005). Word length effect in early reading and in developmental dyslexia. Brain and Language, 93, 369-373. DOI: 10.1016/j.bandl.2004.10.010

Zoccolotti, P., De Luca, M., Di Pace, E., Judica, A., Orlandi, M., \& Spinelli, D. (1999). Markers od developmental surface dyslexia in a language (Italian) with high grapheme-phoneme correspondence. Applied Psycholinguistics, 20, 191-216.

Zoccolotti, P., De Luca, M., Judica, A., \& Spinelli, D. (2008). Isolating global and specific factors in developmental dyslexia: A study based on the rate and amount model (RAM). Experimental Brain Research, 186, 55I-560. DOI: 10.1007/s0022I-007-I257-9 